\section{Triagem sorológica para doença celíaca em adolescentes e adultos jovens, estudantes universitários}

\section{Serological triage for celiac disease in adolescents and young adults attending university}

Ana Carla Augusto Moura 1

Margarida Maria de Castro-Antunes 2

Leandro Alvino Melo de Lima 3

Josemar Maria de Melo Nobre 4

Maria Eugênia Farias Almeida Motta 5

Giselia Alves Pontes da Silva 6

1,2,4 Instituto de Medicina Integral Prof. Fernando Figueira (IMIP). Recife, PE, Brasil.

3 Programa Institucional de Bolsas de Iniciação Científica. Fundação de Amparo à Ciência e Tecnologia do Estado de Pernambuco (PIBIC/ FACEPE). Recife, PE, Brasil.

5,6 Pós-Graduação em Saúde da Criança e do Adolescente. Departamento Materno Infantil. Universidade Federal de Pernambuco. Av. Prof. Moraes Rego, 1235 Cidade Universitária. CEP: 50.670-901. Recife, PE, Brasil. E-mail: giseliaalves@gmail.com

\section{Resumo}

Objetivos: avaliar a positividade sorológica para

Objectives: to evaluate serum for celiac disease in a group of adolescents and young adults in the city of Recife, in the Northeast region of Brazil.

Methods: the sample was made up of students enrolled on undergraduate courses at the Center for Health Sciences of the Federal University of Pernambuco. A blood sample was taken from the students to test their serum for the human tissue antitransglutaminase antibody and they were asked to complete a questionnaire on the symptoms and morbid conditions associated with celiac disease. THE antitransglutaminase was identified using the Elisa technique, taking positive values to be those above 10 $U / m L$, as recommended by the manufacturer. Patients who tested positive for the antitransglutaminase antibody were subsequently tested for the antiendomysial antibody, by indirect immunofluorescence, using the commercially available kit.

Results: six hundred and eight-three university students took part in the study. They were aged between 18 and 30 years, with a mean age of 21 years. The antitransglutaminase antibody was found in 12/683, a prevalence of $1.76 \%$ (CI95\%: 0.95-3.13\%). The antiendomysial antibody test was carried out in eleven these samples and the reagent in four. Eight students tested positive and/or had morbid conditions associated with celiac disease.

Conclusions: the high levels of anti-transglutaminase antibodies found in this study were similar to those found in Europe and the United States suggesting that serological triage can be carried out even in populations considered to be low risk.

Key words Celiac disease, Epidemiology, Seroepidemiologic studies, Diagnosis, Adolescent, Young adult doença celíaca em um grupo de adolescentes e adultos jovens da cidade do Recife, Nordeste do Brasil.

Métodos: a amostra foi composta por estudantes matriculados nos cursos de graduação do Centro de Ciências da Saúde da Universidade Federal de Pernambuco. Os estudantes foram submetidos à coleta de sangue para pesquisa sorológica do anticorpo antitransglutaminase tecidual humana e responderam a questionário sobre sintomas e condições mórbidas associadas à doença celíaca. O anticorpo antitransglutaminase foi pesquisado por técnica de Elisa, considerando-se positivos valores acima de $10 \mathrm{U} / \mathrm{mL}$, conforme estabelecido pelo fabricante. Nos pacientes que tiveram sorologia positiva para o anticorpo antitransglutaminase realizou-se a sorologia para o anticorpo antiendomiseo, por imunofluorescência indireta, utilizando kit comercialmente disponivel.

Resultados: seiscentos e oitenta e três universitários participaram da pesquisa. Os estudantes tinham entre 18 e 30 anos e mediana de idade de 21 anos. $O$ anticorpo antitransglutaminase foi positivo em 12/683, soroprevalência de 1,76\% (IC95\%: 0,95$3,13 \%)$. O anticorpo antiendomíseo foi realizado em 11 amostras e reagente em quatro. Oito estudantes com sorologia positiva tinham sintomas elou condições mórbidas associadas à doença celíaca.

Conclusões: a elevada presença de anticorpos anti-transglutaminase encontrada neste estudo é semelhante a da Europa e Estados Unidos da América, sugere a possibilidade da triagem sorológica mesmo em populações consideradas de baixo risco.

Palavras-chave Doença celíaca, Epidemiologia, Estudos soroepidemiológicos, Diagnóstico, Adolescente, Adulto jovem 


\section{Introdução}

A doença celíaca (DC) é uma doença autoimune desencadeada pelo glúten que ocorre em indivíduos geneticamente predispostos e que pode evoluir com complicações caso não seja identificada e tratada. 1,2 A partir da década de 1980 a doença celíaca deixou de ser considerada uma condição rara e atualmente estima-se que afete entre 0,5 e $1 \%$ da população mundial, com importantes variações regionais. ${ }^{3,4} \mathrm{Em}$ 1997, Dieterich et al. 5 demonstrou que a enzima transglutaminase era na realidade o principal autoantígeno da DC, revolucionando o conhecimento acerca da patogenia da doença e permitindo o desenvolvimento da técnica sorológica que permitia identificar anticorpos contra essa enzima.

A pesquisa do anticorpo antitransglutaminase tecidual - em inglês tissue transglutaminase (tTG), sozinha ou em combinação com o anticorpo antiendomíseo - antiendomiseum antibody (EMA), tem sido amplamente utilizada para triagem sorológica e apoio ao diagnóstico da DC,6,7 precedendo a biópsia do intestino delgado (BID) nos pacientes sintomáticos ou pertencentes a grupos de risco para a doença (familiares de primeiro grau e portadores de diabetes tipo I).2,8,9

$\mathrm{O}$ diagnóstico da $\mathrm{DC}$, segundo os consensos atuais, exige o exame histopatológico da mucosa do intestino delgado e a demonstração de alterações vilositárias na vigência da ingestão de glúten. A presença da sorologia positiva reforça a hipótese diagnóstica e o seu desaparecimento, assim como dos sintomas após três a seis meses de isenção de glúten, dispensa repetir a biópsia para firmar o diagnóstico. 2

Os estudos de soroprevalência servem como estimativa da frequência da DC uma vez que a positividade sorológica guarda relação com a verdadeira prevalência da DC em grandes grupos populacionais. No Brasil, estudos realizados em Brasília, São Paulo e Ribeirão Preto utilizaram amostras de doadores de sangue e encontraram frequência variando entre 0,5 e $1 \%$. Dados semelhantes ou até discretamente superiores aos descritos nos países europeus. ${ }^{9-11} \mathrm{Na}$ Região Nordeste os dois estudos de triagem sorológica que foram realizados até o momento pesquisaram a DC em crianças atendidas nos ambulatórios de um hospital de referência do Recife e em pessoas com suspeita de filariose na cidade de Olinda encontraram positividade para o tTG entre 0,8 e $1,9 \%$, sugerindo que a DC é frequente nessa região. ${ }^{12,13}$

Além disso, a DC considerada tradicionalmente uma doença da infância tem sido cada vez mais diag- nosticada em adolescentes, adultos e também em idosos. ${ }^{14}$ Em adultos, a DC raramente se apresenta com a sua forma clássica, com diarréia, distensão abdominal e desnutrição. Nesses indivíduos predominam sintomas gastrointestinais menos acentuados ou sintomas não relacionados ao sistema digestório, tais como, anemia, fadiga, dor articular, diminuição da densidade mineral óssea, infertilidade e baixa estatura. ${ }^{15-18}$

O perfil epidemiológico e clínico da DC é variável entre as diversas regiões do mundo e refletem a vulnerabilidade genética e fatores ambientais de cada população. Alguns grupos populacionais (adultos e idosos) não tem ainda a frequência da doença celíaca determinada. Nesse sentido, o objetivo desse estudo é determinar a positividade sorológica da doença celíaca em adolescentes e adultos jovens da cidade de Recife, Nordeste do Brasil.

\section{Métodos}

O estudo foi realizado no período de setembro de 2008 a abril de 2009. Os participantes do estudo eram estudantes de graduação do Centro de Ciências da Saúde (CCS) da Universidade Federal de Pernambuco (UFPE).

O recrutamento foi realizado após uma campanha de divulgação com o tema: "Doença Celíaca: você pode ter e não saber", abrangendo os diversos aspectos e potenciais complicações da DC, veiculada por meio de email, panfletos, banner e abordagem direta. Seiscentos e oitenta e três estudantes aceitaram participar da pesquisa. $\mathrm{O}$ estudo foi aprovado pelo Comitê de Ética em Pesquisa em Seres Humanos do CCS da UFPE e todos os participantes assinaram um termo de consentimento livre e esclarecido que lhes garantiu o cumprimento das normas da resolução 196 do Conselho Nacional de Saúde. Os estudantes com sorologia positiva foram encaminhados para prosseguir na investigação para DC e acompanhamento médico especializado.

Os participantes responderam a um questionário estruturado que investigava sintomas sistêmicos (perda ou dificuldade de ganho de peso), gastrintestinais (dor e distensão abdominal, empachamento, diarréia, náuseas, vômitos e constipação), não gastrointestinais (dor articular, fadiga, aftas, irritabilidade, insônia e alopecia) e condições mórbidas associadas à DC (anemia, doenças tireoidianas, depressão, epilepsia, dermatite herpetiforme e doenças reumatológicas) e foram submetidos à punção venosa para coleta de $3 \mathrm{~mL}$ de sangue em tubo seco para obtenção de soro, posteriormente 
congelado a $-20^{\circ} \mathrm{C}$.

A pesquisa do anticorpo antitransglutaminase IgA humano (tTG) foi realizada por meio do kit Biocard Celiac Disease Stick, Ani Biotech Oy, Vtao, Finland ${ }^{\circledR}$, considerando como positivo o valor de $10 \mathrm{U} / \mathrm{mL}$ conforme recomendado pelo fabricante. Nos pacientes com tTG positivo foi realizado pesquisa do EMA, por imunofluorescência indireta, por meio do kit Antiendomysium ${ }^{\circledR 96}$ do Laboratório Eurospital, Trieste, Itália.

As frequências estão descritas em porcentagem com os seus respectivos intervalos de confiança de 95\% (IC95\%) e as idades em mediana e percentis $\left(\mathrm{P}_{25}-\mathrm{P}_{75}\right)$. Utilizou-se o teste do qui-quadrado e Fisher para testar diferenças entre as frequências. Considerou-se o valor do $p<0,05$ como estatisticamente significante. Os dados foram armazenados e analisados usando o software EpiInfo 6.04.

\section{Resultados}

Foram analisados dados de 683 estudantes com idade variando entre 18 e 30 anos, mediana de 21 anos $\left(\mathrm{P}_{25}: 20 ; \mathrm{P}_{75}: 23\right)$ sendo $61,2 \%$ do sexo feminino e $32,0 \%$ do sexo masculino $(p<0,05)$.

O tTG foi positivo em doze estudantes $(1,76 \%$, IC95\%: 0,$95 ; 3,13 \%$ ). Nesses doze indivíduos o tTG apresentou valores séricos entre $10,2 \mathrm{U} / \mathrm{mL}$ e $>200$ $\mathrm{U} / \mathrm{mL}$ (mediana de 13,31 U/mL). Em um dos estudantes com tTG positivo não foi possível realizar EMA por amostra insuficiente e recusa a repetir a coleta. A sorologia para EMA foi positiva em quatro dos 11 estudantes com tTG positiva (4/683).

Dentre os doze estudantes soropositivos para a tTG, dois não registraram seus dados no formulário, embora concordassem em que o resultado da sorologia fosse divulgado. Por esse motivo o sexo, a idade e os sintomas desses pacientes não puderam ser avaliados. Os valores de tTG e EMA assim como, as características dos demais pacientes com tTG positivo estão descritas na Tabela 1 .

\section{Discussão}

Encontramos uma positividade sorológica (tTG) para DC de $1,76 \%$ e, considerando a positividade dos dois anticorpos pesquisado, de $0,58 \%$ Os demais estudos realizados no Brasil até o momento, utilizando diferentes anticorpos, encontraram uma positividade de 0,8 a $1,5 \% 9$-11 e os realizados em populações européias e norte-americanas de 0,5 a $1 \% .1,4$ Sendo que a maioria dos dados citados foi pesquisada em pacientes procedentes de banco de sangue. Os estudos realizados em banco de sangue excluem indivíduos doentes e com anemia, uma das condições associadas à DC, minimizando a soropositividade encontrada. 9,10

Uma das maiores dificuldades em estudos populacionais que envolvem testes sorológicos é o recrutamento de indivíduos que consintam em colher sangue. Um dos pontos fortes desse estudo foi ter sido o único no Brasil, pelo que temos conhecimento até o momento, realizado fora de banco de sangue. Contudo, a amostragem por conveniência e sensibilizada, necessária para adesão a esse estudo, pode ter contribuído para um maior número de indivíduos sintomáticos entre os indivíduos testados o que pode ter superestimado a frequência evidenciada. Além disso, o fato de ter sido realizado com estudantes da área de saúde e predominantemente em mulheres pode ter influenciado nos dados pela sensibilização desses indivíduos para identificar sintomas e maior ocorrência da doença entre mulheres.

Os nossos dados se assemelham aos descritos na Inglaterra em 2003, onde dentre 1000 estudantes de medicina (num desenho de estudo semelhante ao utilizado por nós), foi evidenciada soropositividade para o tTG de 1,7\% (17/1000).19 Em Portugal foi encontrada uma soropositividade para o tTG de $2 \%$ dentre 536 adolescentes; dos onze adolescentes soropositivos para tTG, quatro tinham EMA positivo. 20

Utilizamos a tTG como teste de triagem inicial, seguido de EMA nos indivíduos positivos por conta da tTG ser um exame de menor custo, não operador dependente e automatizado, diferentemente do EMA. Já está descrito que é raro pacientes com tTG normal apresentaram EMA positivo, reforçando que essa estratégia é adequada para triagem para DC na população geral.21,22 Por outro lado, o resultado do EMA guarda correlação com o grau de inflamação da mucosa intestinal e pode estar negativo em pacientes com alterações leves e moderadas, o que ocorre em grande parcela dos portadores de DC. 21 Nesse sentido, atualmente sabe-se que o fato do EMA estar negativo não afasta a possibilidade de DC. 2

Os níveis séricos do tTG parecem refletir o grau de lesão tecidual intestinal em pacientes com DC. 23 Em adultos, foi demonstrado que $96 \%$ dos indivíduos com níveis de tTG maiores ou iguais do que $100 \mathrm{U} / \mathrm{mL}$ apresentavam atrofia vilositária em mucosa intestinal. 24 No nosso estudo, embora os níveis de tTG tenham sido baixos (exceto por um paciente), sete indivíduos se descreviam como sintomáticos, cinco inclusive com anemia crônica, que é uma das condições classicamente descritas como associadas a DC. 25 No entanto, esses indiví- 


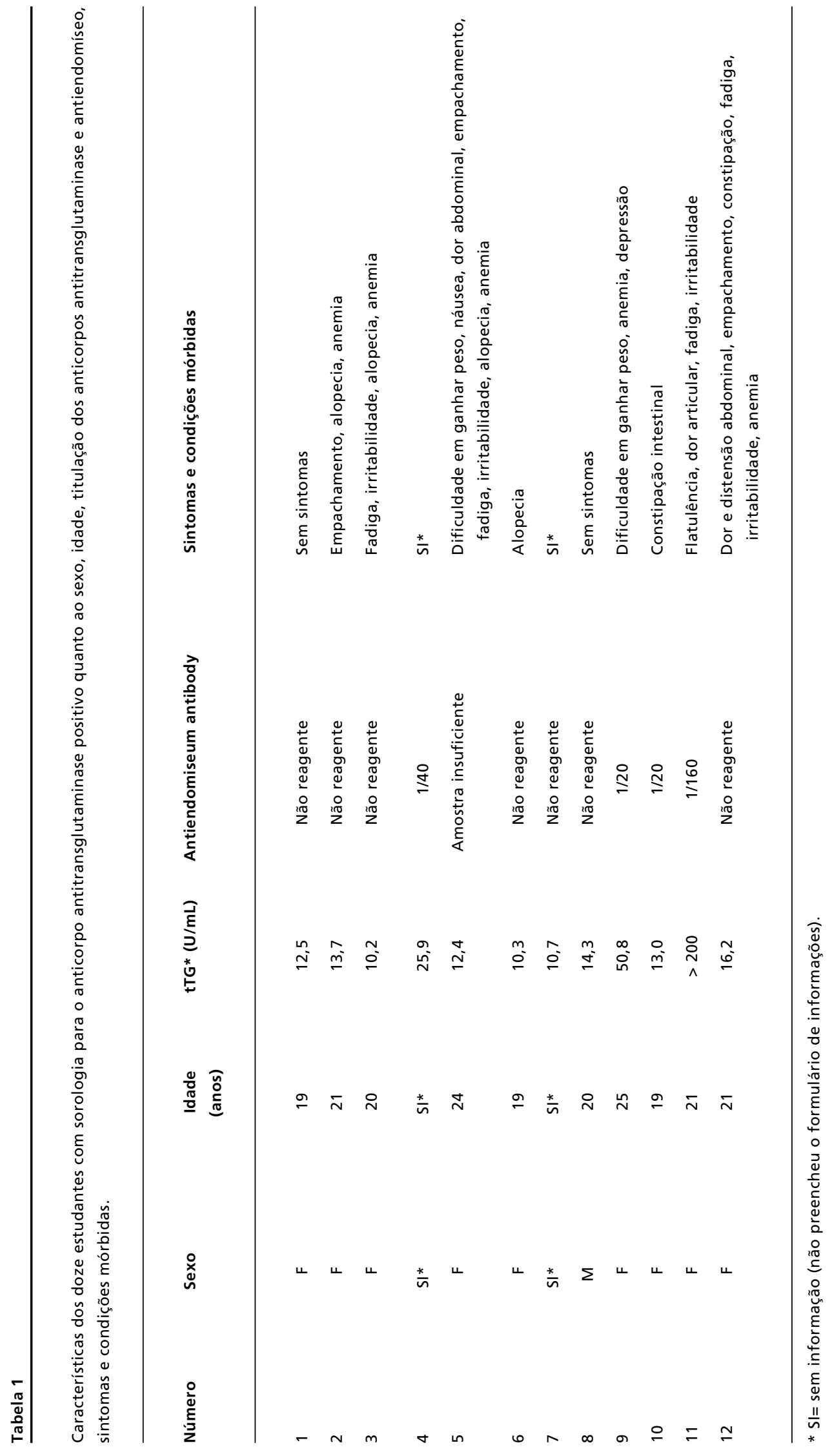


duos não tinham suspeição prévia dessa doença. Interessantemente, os dois pacientes que se diziam assintomáticos tiveram EMA não reagente.

Em 2010 foi publicada revisão sistemática, realizada por grupo do Reino Unido e Holanda, que avaliou os dados de 6085 pacientes com sintomas gastrointestinais, em clínicas gerais, que foram submetidos à sorologia e BID para diagnóstico de doença celíaca. Observa-se que a frequência de DC foi de até $13 \%$ em diversos estudos, porém com grande variabilidade entre eles. ${ }^{26}$ Outros estudos demonstram que a DC é mais frequente em pessoas com síndrome do intestino irritável, dispepsia, constipação e dor abdominal recorrente do que na população geral.17,22 Mesmo assim, ainda é pequena a suspeição para DC em pessoas com sintomas menos acentuados, especialmente em pacientes fora da idade pediátrica. 14,16

É consenso que se deve realizar sorologia para DC em indivíduos pertencentes a grupos de risco, tais como portadores de diabetes tipo I e familiares de primeiro grau de portadores de DC, pois nesses grupos a ocorrência da doença é até vinte vezes superior a da população geral.2,8 Contudo, não existe recomendação de realizar esse procedimento em indivíduos fora de grupo de risco e assintomáticos. Outro questionamento é sobre o benefício do tratamento nos portadores assintomáticos, embora ainda seja consenso indicá-lo, uma vez que se diagnostica a doença (na tentativa de evitar complicações).2,23 Contudo também são esses pacientes que apresentam a menor taxa de adesão ao tratamento dietético. Muitos estudos têm sido conduzidos no sentido de consolidar essas condutas.

$\mathrm{Na}$ literatura, questiona-se sobre a validade de

\section{Referências}

1. Catassi C, Fasano A. Celiac disease. Curr Opin Gastroenterol. 2008, 24: 687-91.

2. Hill ID, Dirks MH, Liptak GS, Colleti RB, Fasano A, Guandalini S, Hoffenberg EJ, Horvath K, Murray JA, Pivor M, Seidman FG. Guideline for the diagnosis and treatment of celiac disease in children: recommendations of the North American Society for Pediatric Gastroenterology, Hepatology and Nutrition. J Pediatr Gastroenterol Nutr. 2005;40: $1-19$

3. Catassi C. Where is celiac disease coming from and why. J Pediatr Gastroenterol Nutr. 2006; 40; 279-82.

4. Fasano A, Berti I, Gerarduzzi T, Not T, Colleti RB, Drago $\mathrm{S}$, Not T, Colleti RB, Drago S, Elitsur Y, Green PH, Guandalini S, Hill ID, Pietzak M, Ventura A, Thorpe M, Kryzak D, Fornalori F, Wassermann SS, Murray JA, Horvath K. Prevalence of celiac disease in at-risk and notat-risk groups in the United States: a large multicenter triagem sorológica para DC em indivíduos sem sintomas ou pouco sintomáticos, 23 mas a elevada soroprevalência encontrada neste estudo sugere a possibilidade da triagem sorológica mesmo em populações consideradas de baixo risco. A presença de sintomas em pacientes com sorologia positiva aponta para a baixa suspeição para a doença celíaca nesse grupo.

Vieira et al.,27 em artigo recente, relata a pouca informação que médicos brasileiros têm sobre a DC onde foi observado que apenas $25 \%$ dos médicos referiram conhecer as formas de apresentação discretas da doença. Daí a necessidade de se dar divulgação mais ampla aos estudos de prevalência e os que relatam as diferentes formas de apresentação clínica da DC.

Nosso estudo endossa a alta frequência de indivíduos portadores de marcadores sorológicos da DC e o baixo grau de suspeição para DC em pacientes sintomáticos fora da faixa etária pediátrica. E com isso chama a atenção da necessidade de uma maior divulgação da DC tanto entre os profissionais de saúde, de forma especial o médico, bem como da população geral.

\section{Agradecimentos}

À Fundação de Amparo a Ciência e Tecnologia do Estado de Pernambuco (FACEPE) pela bolsa concedida ao aluno Leandro Alvino.

A Dr. Sérgio Crovella e equipe pela permissão de processamento das amostras no Laboratório de Virologia do Laboratório de Imunopatologia Keiso Asami (LIKA).

study. Arch Intern Med. 2003; 163: 286-92.

5. Dieterich W, Ehnis T, Bauer M, Donner P, Volta U, Riecken EO, Schuppan D. Identification of tissue transglutaminase as the autoantigen of celiac disease. Nature Med. 1997; 3: 797-801.

6. Feighery C, Conlon N, Jackson J. Adult population screening for coeliac disease: comparison of tissue-transglutaminase antibody and anti-endomysial antibody tests. Eur J Gastroenterol Hepatol. 2006, 18: 1173-5.

7. Poddar U, Thapa RB, Nain KC, Singh K. Is tissue transglutaminase autoantibody the best for diagnosing Celiac Disease in children of developing countries? J Clin Gastroenterol. 2008; 42: 147-51.

8. Castro-Antunes MM, Magalhães R, Nobre J, Silva B, Silva GAP. Celiac disease in first-degree relatives of patients $\mathrm{J}$ Pediatr (Rio J). 2010; 86: 331-6. 
9. Gandolfi L, Pratesi R, Cordoba JCM, Tauil PC, Gasparin M, Catassi C. Prevalence of celiac disease among blood donors in Brazil. Am J Gastroenterol. 2000; 95: 689-92.

10. Melo SBC, Fernandes MF, Peres LC, Troncon LEA. Prevalence and demografic caracteristcs of celiac disease among blood donors in Ribeirão Preto, State of São Paulo, Brasil. Dig Dis Sci. 2006; 57: 1020-5.

11. Oliveira RP, Sdepanian VL, Barreto JÁ, Cortez AJP, Carvalho FO, Bordin JO, de Camargo Soares MA, da Silva Patricio FR, Kawakami E, de Morais MB, Fagundes-Neto U. High prevalence of celiac disease in brazilian blood donor volunteers based on screening by $\operatorname{IgA}$ antitissue transglutaminase antibody. Eur J Gastroenterol Hepatol. 2007; 19: 43-9.

12. Brandt KG, Silva GAP. Soroprevalência da doença celíaca em ambulatório pediátrico, no nordeste do Brasil. Arq Gastroenterol. 2008; 45: 239-42.

13. Crovella S, Brandão L, Guimarães, Filho JL, Arraes LC, Ventura A, Not T. Speeding up coeliac disease diagnosis in the developing countries. Dig Liver Dis. 2007; 39: 900-2.

14. Vilppula A, Collin P, Maki M, Valve R, Luostarinan M, Krelela I, Patrikainen H, Kaukinen K, Luostarinen L. Undetected coeliac disease in the elderly: a biopsy-proven population-based study. Dig Liver Dis. 2008; 40: 809-13.

15. Usai P, Manca R, Cuomo R, Lai MA, Boi MF. Effect of gluten-free diet and co-morbidity of irritable bowel syndrome-type symptoms on health-related quality of life in adult coeliac patients. Dig Liver Dis. 2007; 39: 824-8.

16. Lebenthal E, Shteyer E, Branski D. The changing clinical presentation of celiac disease. Pediatric Adolesc Med. Basel, Karger. 2008; 12: 18-22.

17. Vivas S, Ruiz de Morales JM, Fernandez M, Hernando M, Herrero B, Casqueiro J, Gutierrez S. Age-related clinical serological, and histopathological features of celiac disease. Am J Gastroenterol. 2008; 103: 2360-5.

18. Lohi S, Mustalahti K, Kaukinen K, Laurila K, Collin P, Rissanen H, Lohi O, Bravi E, Gasparin M, Reunnanen A Maki M. Increasing prevalence of celiac disease over time. Aliment Pharmacol Ther. 2007; 26: 1217-25.

Recebido em 3 de outubro de 2011

Versão final apresentada em 13 de março de 2012

Aprovado em 4 de abril de 2012
19. El-Hadi S, Tuthill D, Lewis E, Adisesh A, Moody M, Fifield R, Thomas G, Williams PE, Jenkins $H$. Unrecognised celiac disease is common in healthcare students. Arch Dis Child. 2004; 89: 842.

20. Antunes A, Abreu I, Nogueira A. Primeira determinação de prevalência de doença celíaca numa população portuguesa. Acta Med Port. 2006; 19: 115-20.

21. Reeves GEM, Squance ML, Duggan AE, Murugasu RR, Wilson RJ, Wong RC, Gibson RA, Steele RH, Pollock WK. Diagnostic accuracy of celiac serological tests: a prospective study. Eur J Gastroenterol Hepatol. 2006; 18: 493-501.

22. Akbari RM, Mohammadkhani A, Fakheri H, Javad Zahadi M, Shahbazkhani B, Nouraje M, Sotoudeh M, Shakei R, Malekzadeh R. . Screening of the adult population in Iran for celiac disease: comparison of the tissue-transglutaminase antibody and anti-endomysial antibody tests. Eur J Gastroenterol Hepatol. 2006; 18: 1181-6.

23. Donaldson MR, Book LS, Leiferman KM, Zone JJ, Neuhansen SL. Strongly positive tissue transglutaminase antibodies are associated with Marsh 3 histopathology in adult and pediatric celiac disease. J Clin Gastroenterol. 2008; 42: 256-60.

24. Sausurre P, Joly F, Bouhnik Y. Contribution of autoantibody assays to the diagnosis of adulthood celiac disease. Joint Bone Spine. 2005; 72: 279-82.

25. Ravikumara M, Tuthill DP, Jenkins HR. The changing clinical presentation of celiac disease. Arch Dis Child. 2006; 91: 969-71

26. Shahbazkhani B, Forootan M, Merat S, Akbari MR, Nasserinoshadam S, Vahedi H, Malekzadeh R. Celiac disease presenting with symptoms of irritable bowel syndrome. Aliment Pharmacol Ther. 2003; 18: 231-5.

27. Vieira C, Matos M, Quaresma T, Oliveira J, Ferreira CD, Silva A, Diniz-Santos D, Silva LR. What Do Brazilian Pediatricians Know About Celiac Disease? Dig Dis Sci. 2011; 56:799-804. 